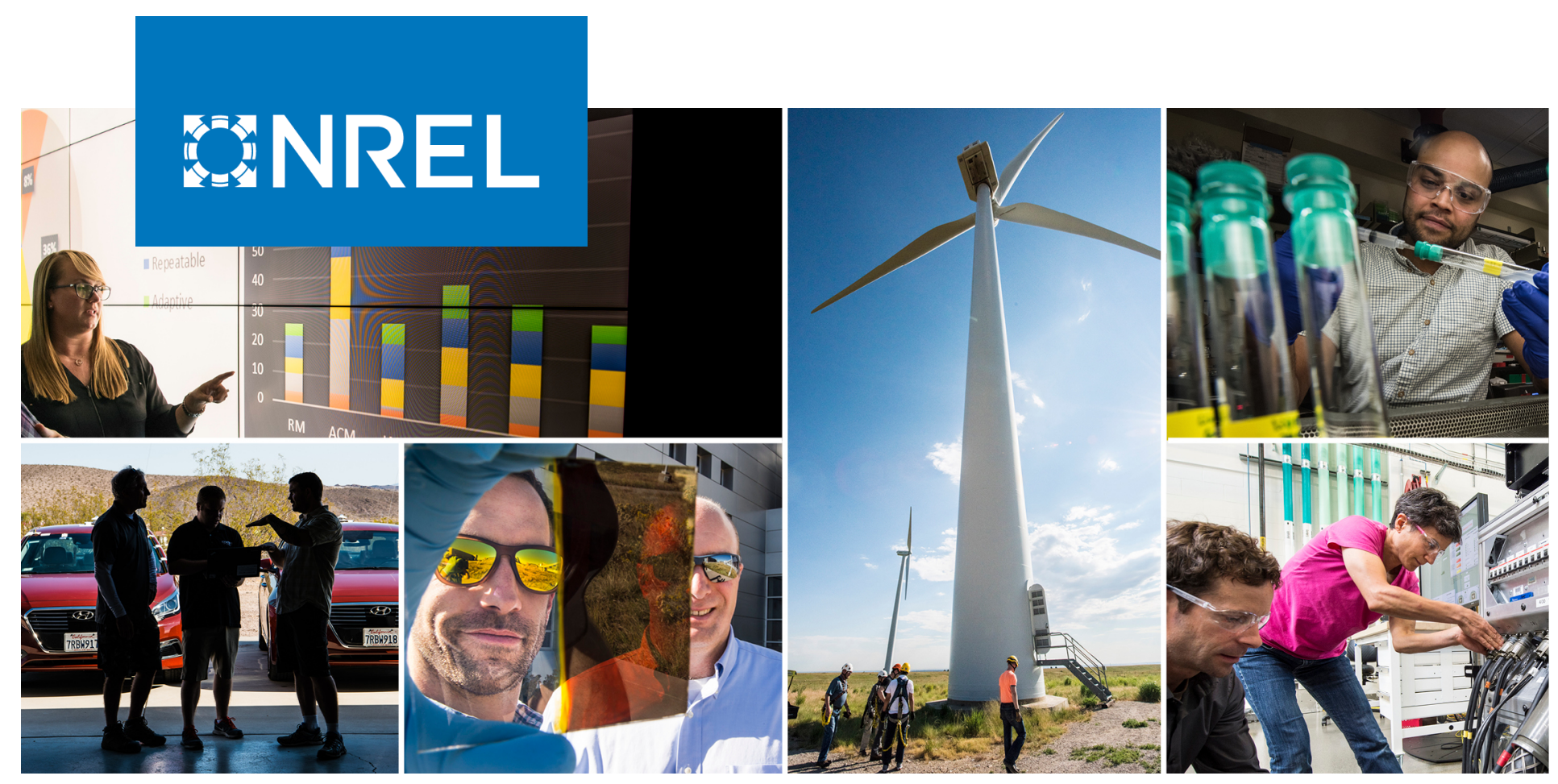

\title{
A Framework for Readiness Assessments of Utility-Scale Energy Storage
}

Amy Rose, Sam Koebrich, David Palchak, Ilya Chernyakhovskiy, and Claire Wayner

National Renewable Energy Laboratory

NREL is a national laboratory of the U.S. Department of Energy

Office of Energy Efficiency \& Renewable Energy

Operated by the Alliance for Sustainable Energy, LLC

This report is available at no cost from the National Renewable Energy Laboratory (NREL) at www.nrel.gov/publications.
Technical Report

NREL/TP-6A20-78197

December 2020 


\title{
GNREL
}

\section{A Framework for Readiness Assessments of Utility-Scale Energy Storage}

\author{
Amy Rose, Sam Koebrich, David Palchak, \\ Ilya Chernyakhovskiy, and Claire Wayner
}

National Renewable Energy Laboratory

\section{Suggested Citation}

Rose, Amy, Sam Koebrich, David Palchak, llya Chernyakhovskiy, and Claire Wayner. 2020. A Framework for Readiness Assessments of Utility-Scale Energy Storage. Golden, CO: National Renewable Energy Laboratory. NREL/TP-6A20-78197.

https://www.nrel.gov/docs/fy210sti/78197.pdf.

NREL is a national laboratory of the U.S. Department of Energy Office of Energy Efficiency \& Renewable Energy Operated by the Alliance for Sustainable Energy, LLC

This report is available at no cost from the National Renewable Energy Laboratory (NREL) at www.nrel.gov/publications.

Contract No. DE-AC36-08GO28308
Technical Report

NREL/TP-6A20-78197

December 2020

National Renewable Energy Laboratory 15013 Denver West Parkway Golden, CO 80401 303-275-3000 • www.nrel.gov 


\section{NOTICE}

This work was authored by the National Renewable Energy Laboratory, operated by Alliance for Sustainable Energy, LLC, for the U.S. Department of Energy (DOE) under Contract No. DE-AC36-08GO28308. Funding provided by the U.S. Department of State through Agreement IAG-17-02055. The views expressed herein do not necessarily represent the views of the DOE or the U.S. Government.

This report is available at no cost from the National Renewable Energy Laboratory (NREL) at www.nrel.gov/publications.

U.S. Department of Energy (DOE) reports produced after 1991 and a growing number of pre-1991 documents are available free via www.OSTI.gov.

Cover Photos by Dennis Schroeder: (clockwise, left to right) NREL 51934, NREL 45897, NREL 42160, NREL 45891, NREL 48097, NREL 46526.

NREL prints on paper that contains recycled content. 


\section{Preface}

This report_-A Readiness Assessment Framework for Utility-Scale Energy Storage — is part of a series investigating the potential for utility-scale energy storage in South Asia. The report forms the basis for forthcoming reports in the series that will provide country-specific evaluations of policy and regulatory environments for energy storage in the region, beginning with India. Those evaluations will provide insights on the opportunities and barriers for energy storage growth and deployment in each country. This report offers the overarching framework for those evaluations.

The framework is designed to allow policymakers and regulators to quickly gauge how well existing policy and regulatory frameworks support investments in energy storage and be applied in any jurisdiction, regardless of its governance, regulatory, or market structure. The report is not designed to recommend specific policy or regulatory solutions, and it does not inform whether energy storage is the best solution among a range of possible technical and nontechnical interventions to meet system needs.

A complementary component of the policy and regulatory analysis for countries in South Asia consists of techno-economic analysis to understand the drivers of energy storage investments in the region. Using NREL's power system planning and operational models of South Asia, this analysis will identify potential storage applications and growth opportunities under various cost, policy, and demand growth scenarios. In addition, the regulatory and policy barriers and incentive mechanisms identified in the energy storage readiness assessments will be incorporated into the modeling to understand their impact on energy storage deployment and operation. Together these studies will inform the applications and value of energy storage for power systems in South Asia, and policy and regulatory pathways to realize this value. 


\section{Acknowledgments}

The authors are greatly indebted to several individuals for their thoughtful feedback and guidance, including Mark Pituch and Ruth Ku (U.S. Department of State). And thank you to Bethany Frew, Owen Zinaman, and Jaquelin Cochran (NREL) for their reviews and to Mike Meshek for editorial assistance. Any errors and omissions are solely the responsibility of the authors. This work was funded by the U.S. Department of State, Bureau of Energy Resources. 


\section{List of Acronyms}

AGC

CSR

ERCOT

ESS

FERC

GW

MW

MWh

NREL

NYSERDA

PJM

RPS

VRE automatic generation control

codes, standards, and regulations

Electric Reliability Council of Texas

energy storage systems

Federal Energy Regulatory Commission (United States)

gigawatt

megawatt

megawatt-hour

National Renewable Energy Laboratory

New York State Energy Research and Development Authority

PJM Interconnection

renewable portfolio standard(s)

variable renewable energy 


\section{Executive Summary}

The global electric power sector is transforming as a result of higher levels of renewable energy, greater amounts of distributed energy resources, and shifting demand patterns resulting from the electrification of the economy. And the transformation presents new challenges and opportunities in operating and maintaining a reliable power system. Energy storage technologies have the potential to help meet these challenges by increasing the flexibility of the power system and contributing to system strength. Declining costs for some energy storage technologies make them an increasingly cost-effective solution to provide a wide range of grid services. However, the potential for energy storage deployment on the grid depends on many factors, including physical characteristics of the power system and the policy and regulatory environments in which investments would operate.

In this report, we aim to inform a broader dialogue about enabling energy storage investments through the development of a framework for conducting energy storage readiness assessments. Our target audience includes policymakers and system operators in South Asia who are considering the impacts that energy storage could have on their grids. Other readers with expertise in wholesale markets, policy, or technical implementation may also benefit from the framework we propose.

The energy storage readiness assessment we describe identifies 20 criteria that enable utilityscale energy storage investments (Tables ES- 1, next page). And it includes a simple evaluation system (Figure ES-1) to identify barriers and opportunities for energy storage within a given power system and policy and regulatory environment.

\section{Status Grade Description}

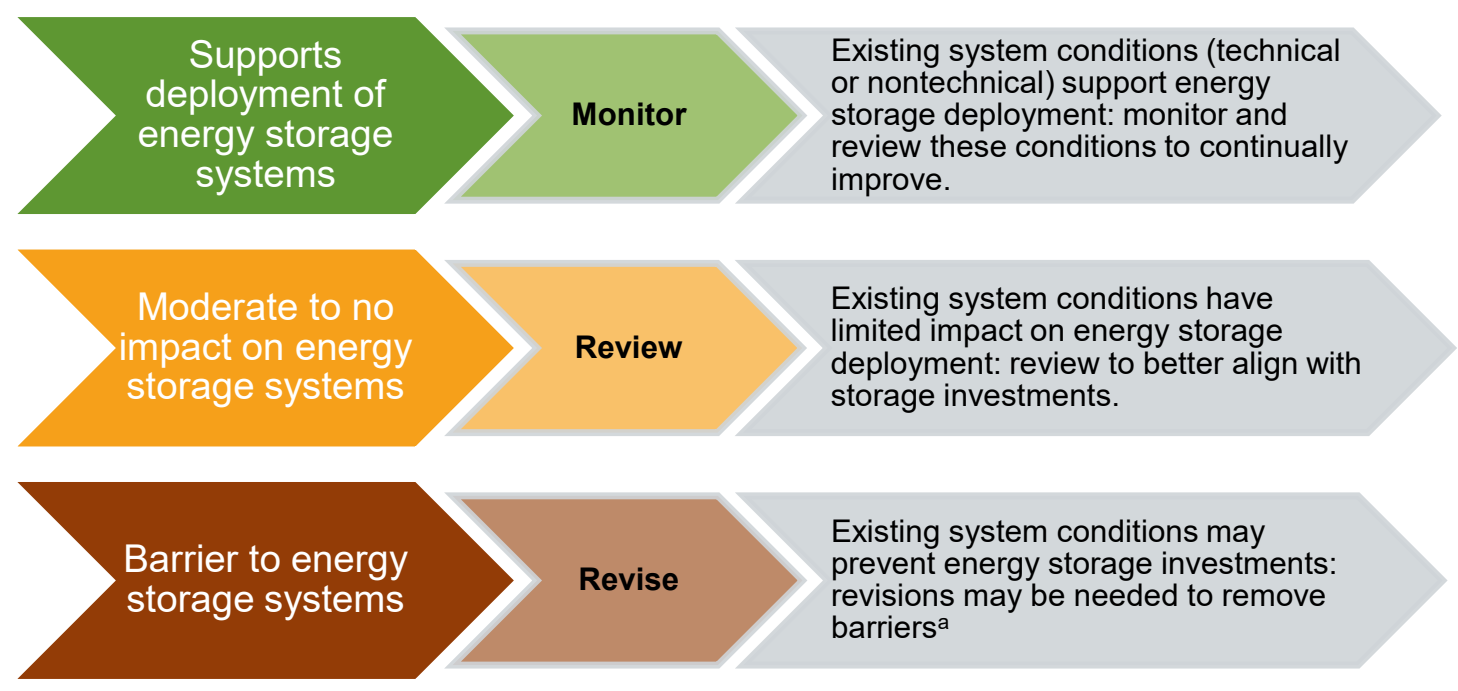

Figure ES-1. Evaluation scheme for energy storage readiness assessment

a Revisions may not be recommended for system characteristics where conditions that are good for the overall system (i.e., high levels of system flexibility and reliability) may not support energy storage investments. 
Table ES-1. Components of the Energy Storage Readiness Assessment

\begin{tabular}{|c|c|c|}
\hline Topic & No. & Criteria \\
\hline \multirow{7}{*}{$\begin{array}{l}\text { System } \\
\text { Characteristics }\end{array}$} & 1 & Low or decreasing load factor in electricity demand \\
\hline & 2 & Inadequate or costly provision of ancillary services \\
\hline & 3 & Inadequate or costly supply options during peak demand periods \\
\hline & 4 & Increasing levels of transmission congestion \\
\hline & 5 & Proposed network upgrades with low anticipated utilization \\
\hline & 6 & Low flexibility in the generation mix \\
\hline & 7 & Increasing curtailment of variable renewable energy \\
\hline \multirow{6}{*}{ Policy } & 8 & Inclusion of storage in energy policy and master plan \\
\hline & 9 & Targets for storage deployment \\
\hline & 10 & Energy strategy promotes operational flexibility \\
\hline & 11 & $\begin{array}{l}\text { Support for organized knowledge sharing and delivery for scale-up } \\
\text { and replication }\end{array}$ \\
\hline & 12 & Domestic industrial policy supports storage manufacturing \\
\hline & 13 & Targeted support to early adopters \\
\hline \multirow{7}{*}{ Regulation } & 14 & Utilities and private developers allowed to make storage investments \\
\hline & 15 & $\begin{array}{l}\text { Interconnection processes give energy storage the right to interconnect and } \\
\text { obtain transmission service }\end{array}$ \\
\hline & 16 & $\begin{array}{l}\text { Promotion of high-quality standardized technologies through safety standards } \\
\text { for storage technologies }\end{array}$ \\
\hline & 17 & Operating requirements for fast-responding assets \\
\hline & 18 & $\begin{array}{l}\text { Electricity service charges reflect the value and increase price transparency for } \\
\text { energy services }\end{array}$ \\
\hline & 19 & Storage able to compete with other grid assets to provide multiple services \\
\hline & 20 & Storage able to receive revenue for providing multiple services \\
\hline
\end{tabular}

In this report, we seek to identify the barriers and opportunities for utility-scale energy storage; therefore, we do not address applications for distributed energy storage, rural grid or stand-alone systems, or electric mobility. Though there surely are separate and overlapping opportunities for these applications, policymakers and market participants are less able to directly engage in these sorts of projects to drive immediate impact. However, many of the criteria we discuss deserve consideration in the context of distributed energy resources. Importantly, we do not inform whether energy storage is the best solution - among a wide range of possible technical and nontechnical interventions - to meet emerging system needs.

The energy storage readiness assessment framework we outline is designed to help policymakers and regulators identify priority areas for focus as they continue to develop appropriate suites of policies, programs, and regulations to enable energy storage deployment. Though we draw from relevant examples from the United States and elsewhere to illustrate how energy storage challenges are being addressed in practice, the goal of our proposed readiness assessment is not 
to recommend specific policy or regulatory solutions but rather to illustrate how compatible a given system might be for energy storage investments and to identify priority areas that might need attention. In fact, our readiness assessment framework is designed to be applied to any jurisdiction regardless of its governance, regulatory, or market structure. 


\section{Table of Contents}

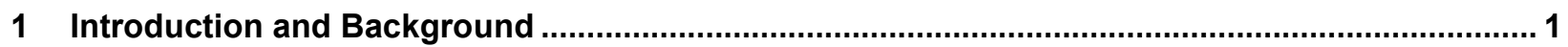

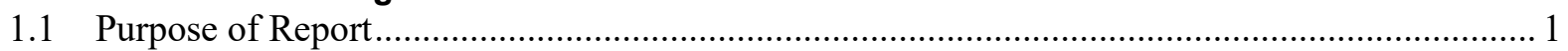

1.2 The Roles of Energy Storage in Power Systems ................................................................ 2

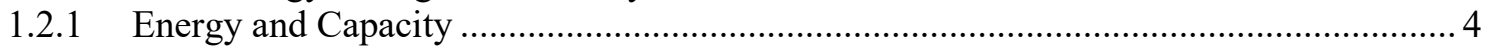

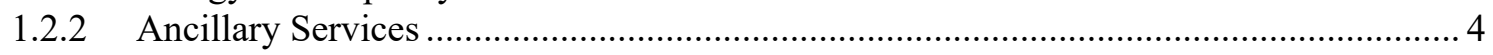

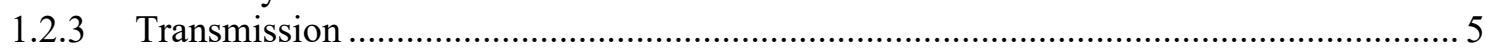

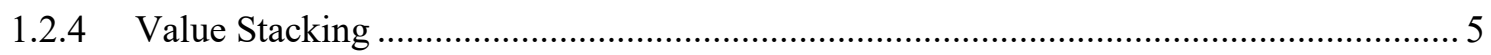

2 What Enables Energy Storage Deployment? …..................................................................... 5

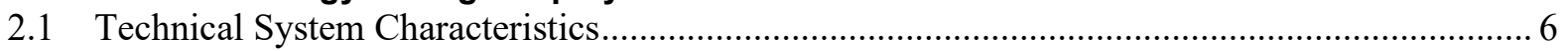

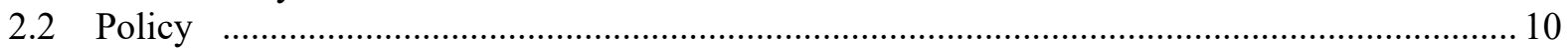

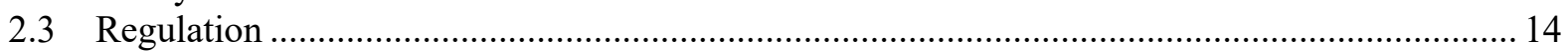

3 The Energy Storage Readiness Assessment Framework .................................................... 20

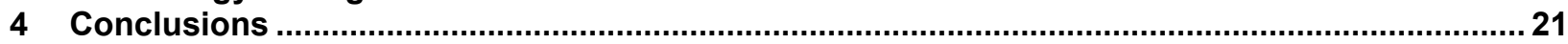

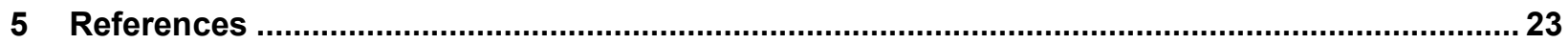




\section{List of Figures}

Figure ES-1. Evaluation scheme for energy storage readiness assessment ............................................vi

Figure 1. Fast frequency response changes to ERCOT's ancillary services........................................... 17

Figure 3. Evaluation scheme for energy storage readiness assessments ................................................ 21

\section{List of Tables}

Table ES-1. Components of our Energy Storage Readiness Assessment................................................vii

Table 1. Services Energy Storage Can Provide at Bulk System Level ....................................................... 3 


\section{Introduction and Background}

\subsection{Purpose of Report}

The electric power sector is transforming from a system with large centralized thermal and hydro power plants to one with higher levels of renewable energy, greater amounts of distributed energy resources, and shifting demand patterns resulting from the electrification of the economy. And the transformation presents new challenges in balancing supply and demand. Energy storage has the potential to help meet these challenges by increasing the flexibility of the power system, and declining costs for some energy storage technologies make it an increasingly cost-effective option. However, the potential for energy storage deployment on the grid depends on many factors, including physical characteristics of the power system and the policy and regulatory environments in which these investments would operate.

This report was prepared by the National Renewable Energy Laboratory (NREL) with support from the U.S. Department of State to inform a broader dialogue about enabling energy storage investments around the world. In this report, we offer an overarching framework in the form of an energy storage readiness assessment for policymakers and regulators to identify priority areas for focus as they continue to develop the appropriate suite of policies, programs, and regulations to enable energy storage deployment. Throughout the report, we provide relevant examples from the United States and elsewhere to demonstrate how emerging challenges related to energy storage are being addressed in practice.

This report addresses utility-scale storage. The report does not address applications for distributed energy storage ${ }^{1}$ (i.e., storage connected to low- and medium-voltage networks), rural grid or stand-alone systems, or electric mobility. Importantly, the report does not inform whether energy storage is the best solution - among a wide range of possible technical and nontechnical interventions - to meet system flexibility needs (Text Box 1).

\footnotetext{
${ }^{1}$ See (Aznar, Bowen, and Zinaman 2020) for detailed discussion of policy and regulatory design of distributed energy-plus-storage systems.
} 


\section{Text Box 1. Sources of power system flexibility}

Power system flexibility is "the ability of a power system to reliably and cost-effectively manage the variability and uncertainty of demand and supply across all relevant time-scales, from ensuring instantaneous stability of the power system to supporting long-term security of supply" (Zinaman and Sadamori 2018). As power systems transform to integrate increasing levels of variable renewable energy and distributed generation, policymakers, regulators, and utility grid operators may need to undertake a series of interventions to maintain the security of supply and avoid excess curtailment (reduction in the output) of wind and solar generation. Flexibility in the power system can come from four categories of grid infrastructure (see Cochran et al. [2014] for details about each category):

- Flexible Generation: power plants and energy storage sources that respond quickly to meet energy demand with few operational constraints (e.g., ramp rates, minimum generation levels, or high start-up costs)

- Flexible Transmission: grid system infrastructure that provides sufficient capacity and control capabilities to enable sharing of flexible resources across supply-demand balancing areas

- Flexible Demand-Side Resources: demand-side infrastructure that enables demand response, storage, distributed generation, and other customer-sited smart grid technologies to respond to electricity market signals or grid operator controls

- Flexible System Operations and Electricity Markets: operating practices and market rules, such as the frequency of market settlements and dispatch instructions that provide access to the inherent flexibility of existing grid infrastructure.

Energy storage is one of several interventions that decision makers can use to increase flexibility. A cost-effective approach for increasing power system flexibility is to evaluate all the options, including supply-side, demand-side, electricity market, and operational interventions that are part of a flexibility portfolio. Planning tools and approaches, including capacity expansion studies, production cost studies, integrated resource and resilience planning, and stability studies, can help inform decision makers about which source of flexibility (including energy storage) may be needed, which specific flexibility issues they can help address, and when they are more cost-effective than other options.

\subsection{The Roles of Energy Storage in Power Systems}

Energy storage has the potential to help meet the emerging challenges associated with the changing power system and to accelerate the deployment of renewable energy. Previous analysis of utility-scale energy storage has identified several potential applications for storage at the bulk system level. Table 1 shows the range of services identified and the time-scale at which these services would be provided. Some forms of energy storage, such as pumped hydro storage have a history of operation in South Asia. India has seven operating pumped hydro storage facilities with a total operable capacity of $3.3 \mathrm{GW}$, along with $2.6 \mathrm{GW}$ under construction and an additional 3.8 GW under survey for development (CEA 2019; 2020). 
Table 1. Services Energy Storage Can Provide at Bulk System Level

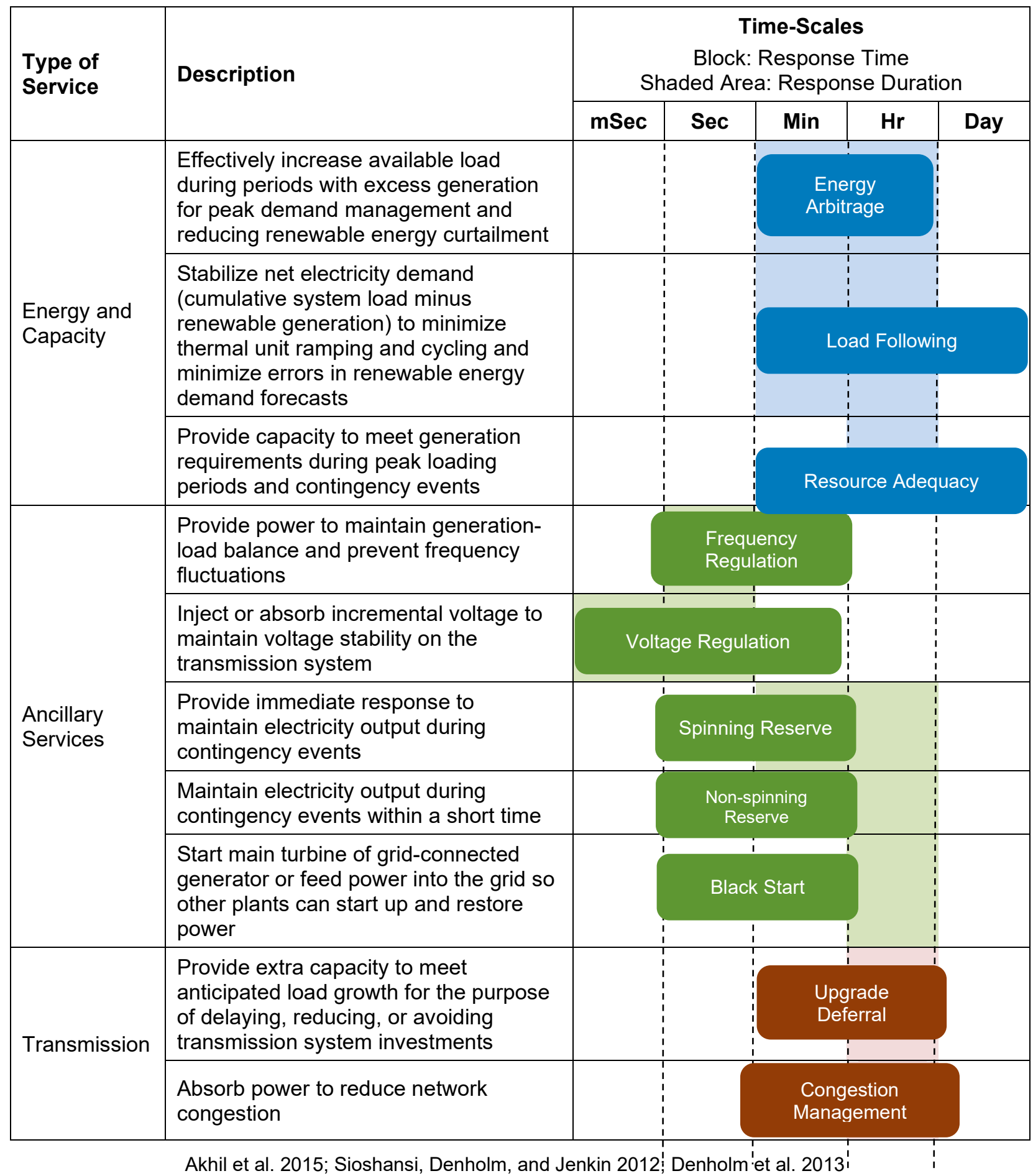




\subsubsection{Energy and Capacity}

Energy storage can enable more-efficient use of existing generation resources and potentially delay, reduce, or avoid the need for investments in new generation capacity.

Energy arbitrage involves storing energy (e.g., charging a battery or pumping water) during periods with excess generation or low energy prices and then discharging during periods with high prices or high demand. Within organized wholesale electricity markets, this practice can increase income for energy storage owners by capturing higher market prices. When operating outside electricity markets, system operators can benefit from energy storage for peak demand management and load-following services. By storing energy during periods of excess generation and dispatching during periods of rapid changes in net electricity demand (i.e., load minus renewable energy generation), energy storage can minimize thermal unit ramping and cycling to improve the economic efficiency of the power system.

Energy storage can also reduce renewable energy curtailment. For renewable energy generators, curtailment can occur when higher levels of inflexible capacity are committed or when demand for the generation locally is insufficient and transmission congestion prevents the delivery of renewable electricity to neighboring regions. The amount of curtailment may impact the economic feasibility of investments in renewable energy technologies. Energy storage can reduce curtailment and maximize the value of renewable energy investments by effectively increasing demand during periods with excess renewable energy generation.

System planners concerned with resource adequacy must maintain adequate reserve capacity to reliably meet demand during the highest demand hours. This demand is typically met by technologies such as gas-fired power plants that have lower investment costs and higher operating costs. For power systems with low load factors - such as those that experience large diurnal fluctuations in demand - energy storage could displace peaking generation capacity. Wind and solar resources can also contribute to meet resource adequacy requirements, but their contribution depends on how well the underlying resource reliably coincides with peak demand. Pairing wind and solar with energy storage could enable these resources to shift their generation to coincide with peak demand, improving their capacity contribution (Denholm and Margolis 2018). To adequately evaluate the capacity value that energy storage resources provide to resource adequacy requirements, probabilistic methodologies of determining capacity value can be used to estimate the actual value provided toward reducing loss of load (Frew et al. 2018).

\subsubsection{Ancillary Services}

System operators use various categories of ancillary services that function on different timescales to continuously maintain a balance of generation and demand. Some energy storage technologies, such as batteries, can respond to signals to charge and discharge in less than a second, making them highly suitable for providing short-term reliability services such as frequency and voltage regulation.

Storage technologies that can discharge over longer periods can provide spinning and nonspinning reserves to maintain electricity output during contingency events. This can help system operators avoid the fuel costs and emissions associated with maintaining a thermal generator online or ready to start to provide these services. Energy storage can also be used to start up other large generators during a system failure when electricity from the grid is unavailable. This 
service, which is called a black start, is typically provided by on-site sources of electricity such as diesel generators. An adequately sized on-site energy storage technology can also provide this service and can avoid the need for conventional black-start generators (Jain et al. 2020; Bowen, Chernyakhovskiy, and Denholm 2019).

\subsubsection{Transmission}

The transmission network is designed for peak demand conditions, which may only occur a few hours of the year. In addition, transmission costs are highly subject to economies of scale, and it is often more economic to add transfer capacity in large increments. As a result, transmission investments tend to be overbuilt for the existing system and a new line may not be fully utilized for many years. Energy storage can delay, reduce, or avoid the costs of transmission investments by providing extra capacity to meet peak demand needs on specific lines.

Energy storage can also improve network operations by absorbing or injecting power to reduce congestion and improve overall transmission utilization. As the patterns of network flows change in response to changes in demand or investments in generation and transmission assets, some energy storage technologies can be relocated when no longer needed, increasing their overall value to the grid (Bowen, Chernyakhovskiy, and Denholm 2019). For example, New York City utility Con-Ed is piloting a mobile tractor-trailer-based 1-MW/4-MWh battery storage system that readily relocates to where it is most useful (Maloney 2017).

\subsubsection{Value Stacking}

Some energy storage technologies can maximize their value to the system by providing multiple services, which is known as "value stacking." For example, a battery storage project that stores excess renewable energy generation during the day and discharges in the evenings to meet peak demand could help reduce renewable energy curtailment and could defer the need for new transmission and generation.

The ability for energy storage technologies to maximize value across multiple services depends in part on the operating requirements (e.g., duration and depth of discharge and response time). Optimizing a storage system's technical characteristics for any single application or group of applications may exclude other potential uses. If a system could be configured to provide multiple services, a high degree of coordination would be required to optimize the use of the stored energy across each service. Without proper coordination, unintended consequences could occur, such as overloading infrastructure when trying to provide services on the bulk power system. Finally, providing multiple services may require operating an energy storage technology at suboptimal levels through, for example, increased cycling. This could lead to increased operating costs and accelerated degradation of the technology, reducing its economic lifetime. Thus, the additional costs of value stacking must be weighed against the benefits of capturing multiple revenue streams (Aznar, Bowen, and Zinaman 2020).

\section{What Enables Energy Storage Deployment?}

Energy storage technologies can help strengthen and stabilize the electric grid by providing a wide range of grid services. However, technical capabilities alone do not guarantee successful uptake of energy storage technologies. The deployment of energy storage depends on the needs of the power system and the existence of policy and regulatory environments to enable energy storage to meet 
those needs. This section presents a series of technical, policy, and regulatory criteria that support energy storage adoption. These criteria form the basis of the energy storage readiness assessment presented in Section 3.

\subsection{Technical System Characteristics}

Energy storage can step into a variety of roles_-providing solutions to other conditions that commonly afflict rapidly changing grids, such as decreasing load factor, inadequate ancillary service availability, or increasing levels of localized transmission congestion. Such issues can be thought of as technical system characteristics that qualitatively describe the power system. These characteristics can help identify whether there is a technical or economic need for utilityscale energy storage in a given system.

\section{Low or Decreasing Load Factor in Electricity Demand}

Load factor is an expression of the utilization of the system. A typical formula for calculating load factor is the average load divided by the maximum load. The result provides an indication of the percentage of available system assets (including generation, transmission, and distribution) needed over a given period. The time scale assessed is commonly a year but could be a season, week, or even a day. Similarly, load factor can be assessed across an entire grid, a service territory, a feeder, or an individual building.

Low load factors indicate volatility in demand and sometimes require that capital-intensive generation or transmission resources be built to serve load only for a short time (O'Neill et al. 2019). Load factors provide a powerful heuristic to estimate patterns of volatility and reliability of the system. In extreme cases, low load factors lead to spikes in energy prices because expensive generating units or unscheduled load shedding is needed if demand exceeds available generation or transmission capacity. In evolving grids that are experiencing rapid customer uptake of new technologies (e.g., electric vehicle chargers), customer utilization of these technologies may coincide with the existing system peak load, further decreasing the load factor (Shenot, Lazar, and Shipley 2018).

In cases where peak load does not coincide with resource availability, the least-cost solutions to mitigate low or decreasing load factors involve shifting load to other periods to lower the system's peak load while simultaneously increasing the average system load (Gumilar et al. 2020). Energy storage facilities present one viable option to achieve the desired load shifting by providing flexible capacity to meet periods of peak demand while managing charging during lower utilization hours to help increase load factor.

\section{Inadequate or Costly Provision of Ancillary Services}

Ancillary services include services in addition to the provision of energy to maintain operational reliability. These services respond across small time-scales (milliseconds to minutes) to balance supply and demand. Signs of inadequate ancillary services include brownouts or equipment faults caused by frequency or voltage fluctuations outside acceptable ranges, which may significantly affect power quality. The consequences of these faults, which have cost implications, include reduced lifetime of power sector infrastructure (e.g., substations and transformers), strain on inertia-driven synchronous generators, and potential damage to customer 
owned appliances. ${ }^{2}$ Providing ancillary services can also be costly if the mechanism for procuring them reduces the opportunities for generators to provide energy or requires reinforcing inadequate transmission capacity.

Ancillary services are typically subdivided into three categories: frequency, voltage, and operating reserves. Frequency regulation are services that seek to maintain a constant oscillation of alternating current across power systems, typically at either 50 or $60 \mathrm{~Hz}$ synchronously across an entire country or region. If demand exceeds supply - as caused by a large load like a railway or water pump turning on, or a generator or transmission line falling offline - the frequency will decline across the entire system. Likewise, if generation exceeds load, the frequency will increase. Significant deviations in either direction can be damaging to appliances and other grid assets. To control frequency, utilities often implement automatic generation control (AGC) systems, which dictate exact generation requirements to a network of generators. However, this can be technically difficult to implement because of communication infrastructure requirements. Alternatively, inertia driven synchronous generators (e.g., coal and natural gas generators) may use mechanical governors to compensate and correct deviations, although doing so may cause premature mechanical wear to the generator if over-relied upon (Chernyakhovskiy et al. 2019; Ela and R.B. Hytowitz 2019). Energy storage can provide frequency response services by using advanced inverter capabilities to respond nearly instantaneously to signals dictating its charging or discharging.

Voltage regulation involves delivering a consistent and safe voltage across transmission lines and throughout the various feeders comprising a power system. Voltage may "droop" when distance from the generation source increases because of electrical resistance. Conversely, distributed generation without proper mitigating equipment may cause voltage to spike on certain lines. To control voltage on the transmission system, some generators can adjust their voltage to compensate for deviations. Additional system upgrades such as transformers and load tap changers can improve persistent voltage issues in specific locations (Denholm, Sun, and Mai 2019). The smaller footprint of energy storage projects can provide voltage regulation services by offering voltage services at any distance from centralized generators.

Operating reserves (e.g. spinning, non-spinning, and ramping services) are generation capacity resources available to respond within minutes to imbalances in supply and demand. Because of the fast response time requirement, spinning reserves are kept as unused capacity on active generators, as opposed to generation resources that are offline and need time to warm up. For example, a 500-megawatt (MW) natural gas fired generator may offer $450 \mathrm{MW}$ to an energy market and reserve $50 \mathrm{MW}$ for unexpected supply-demand imbalances. Like frequency response, energy storage can be controlled to offer dependable and fast responding operating reserves without requiring mechanical inertia. And the fact that is does not have to be online means energy storage can avoid the costs associated with remaining synchronized to the grid and potentially replace other generators that are kept online for spinning reserves.

\footnotetext{
2 "Inertia" refers to the energy stored as kinetic energy in large rotating masses, such as from thermal power plants which have spinning turbines. This inertia has traditionally served a purpose of stabilizing the grid, but it could technically be served by various energy storage technologies.
} 
In addition to providing traditional operating reserves, energy storage offers new solutions to power quality issues. For instance, voltage or frequency spikes often offer opportunities to economically increase load (e.g., by charging a battery) to restore the system. Other forms of battery storage such as mechanical flywheels have demonstrated an ability to economically provide large sums of capacity for frequency response on much faster time-scales than has previously been provided by inertia driven generators. In markets where a diminished quality of service is being provided to customers because of inadequate ancillary services, there could be a potential market for energy storage.

\section{Inadequate or Costly Supply Options During Peak Demand Periods}

When load factors are low, the system must maintain generation resources with low utilization to serve peak demand. These resources, which are designed to be used during only a few hours of the year, often have higher operating costs and can lead to increased costs of supply being passed on to consumers. In jurisdictions lacking the domestic oil, gas, or coal supplies required to power these plants, there is an added exposure to price volatility in international energy commodity markets.

Though natural gas has emerged globally as a peaking power source, storing natural gas can be logistically difficult. Storage - in particular, battery storage paired with renewables - offers a reliable alternative with no exposure to the price fluctuations of international commodity markets. Underscoring this fact, a 2019 economic analysis in India found the cost of supply from solar photovoltaic plus one-hour of battery storage was less expensive over the project lifetime than a comparable gas plant used for meeting peak demand, and longer duration stand-alone battery storage projects are expected to be cost-competitive with gas power projects by 2025 (Abraham 2019).

The duration of storage projects and the requirements of the system are an important consideration when comparing energy storage to traditional peaking resources. For example, most lithium-ion battery technologies are configured to deliver either 2 or 4 hours of continuous discharging at the rated nameplate power. It is possible to discharge for a longer duration at a lower power output, but there are cost and benefit trade-offs when deciding the power and capacity (duration) when configuring an energy storage system. Energy storage as a peaking resource will be less expensive when the anticipated duration of the peak is shorter, but storage does offer flexibility to dispatch for a longer duration at a lower rated output.

\section{Increasing Levels of Transmission Congestion}

The transmission network is an essential part of any power system because it facilitates power exchanges between network users. Transmission lines allow for generation to move from supply regions to load centers while smoothing imbalances in the cost of supply across the grid. When inadequate transmission capacity exists, transmission lines can become congested and impact the amount of power that can flow across the entire network.

Transmission congestion can lead to inefficient use of grid assets, as some low-cost generators may be prevented from injecting power onto the grid because of localized network constraints. Network constraints can also result in long queues for new generation projects to be approved to export to the transmission system. Energy storage can alleviate localized transmission congestion 
and stabilize network flows by absorbing excess power on congested lines and discharging during periods when power flows are low.

\section{Proposed Network Upgrades with Low Anticipated Utilization}

Increased transmission capacity is a key and often overlooked tool when integrating renewable energy resources into a grid. However, the unique properties of electricity transmission present a barrier for achieving adequate transmission investments in a timely manner. Transmission facilities cannot be freely designed because investments are discrete (i.e., one cannot build half a line) and only a handful of standard voltage levels and configurations are technically feasible. In addition, transmission costs are highly subject to economies of scale. Per-unit line costs increase linearly with the line's voltage rating while transfer capacities grow approximately with the voltage squared. Because it is more economic on a per-unit basis to add transfer capacity in large increments rather than continuously, planned transmission investments tend to be overbuilt for the existing system and, as a result, a new line may not be fully utilized for many years.

Though new transmission projects often require extensive planning, review, and construction processes that can stretch project timelines across 5-10 years (Donohoo-Vallett, Milligan, and Frew 2015), energy storage offers an alternative solution that can be quickly implemented. Energy storage facilities that can defer or reduce the need for transmission upgrades can also be more economic, particularly in systems with a low load factor where a new transmission lines would have a low level of utilization and would be prohibitively expensive to build (Eyer 2009). Storage can be deployed incrementally, unlike new transmission lines, which require a significant up-front cost and a lengthy project development timeline. Projects demonstrating the potential of storage for transmission deferral have been successfully developed in California and Arizona, where utilities were approved by regulators to procure battery storage rather than make immediate transmission infrastructure investments (Maloney 2017). Thus, in markets where new network upgrades are needed with low anticipated levels of utilization, there may be a potential market for energy storage.

\section{Low Flexibility in the Generation Mix}

All power systems have some inherent flexibility to respond to fluctuations in supply and demand. Power plants can ramp up and down in response to demand needs, transmission enables balancing with neighboring systems, and demand-side resources allow customers to adjust their consumption in response to system conditions. Wind and solar generation can increase the need for system flexibility from other grid resources. In particular, higher penetrations of variable generation can increase the system's ramping requirements, require committed units to operate at lower levels, and shorten peak net demand periods (Denholm and Margolis 2018). Inflexible power systems may experience difficulty balancing supply and demand, resulting in frequency excursions or dropped load and significant renewable energy curtailment. In jurisdictions with wholesale power markets, negative market prices and large swings between low and high prices can also indicate inadequate system flexibility (Cochran et al. 2014).

Energy storage can increase grid flexibility by reducing curtailment of variable resources and reducing ramping strain on conventional power plants. This concept is being demonstrated in Europe, especially in countries such as Germany, which have substantial low-flexibility coal resources paired with an increasing share of renewable energy deployment. Germany is projected to have the largest energy storage market in Europe by 2040, with upwards of 24 gigawatts 
(GW) of non-hydro storage capacity - compared with $9 \mathrm{GW}$ of gas peakers and $7 \mathrm{GW}$ of pumped storage hydropower-which would make energy storage Germany's primary peaking resource (McCarthy and Eager 2020). In markets dominated by traditional baseload sources of generation, requiring the addition or replacement of peaking resources may offer potential for energy storage.

\section{Increasing Curtailment of Variable Renewable Energy}

When variable renewable energy (VRE) generation is noncoincident with load, there may be periods when VRE generation cannot be fully used by the system and must be curtailed. Possible causes include high VRE resource availability, transmission congestion, or minimum thermal generator output levels (Penn State 2019). In jurisdictions with wholesale markets, this situation has caused dramatic decreases in real-time wholesale energy prices, with prices sometimes approaching zero or even negative values (Gimon, Orvis, and Aggarwal 2015).

Curtailment has adverse economic effects on renewable generators that require revenue from power generation to service project debt. There are also environmental concerns, as negative market prices usually indicate that conventional generators are displacing available renewable energy. Increasing levels of VRE curtailment indicates a need increased system flexibility. Many energy storage technologies are capable of storing excess renewable generation and discharging during periods when demand is higher, thus providing increased system flexibility and increasing revenue for renewable generators.

\subsection{Policy}

Most markets are in a familiarization phase with energy storage. Though awareness of the potential of energy storage has spread, many decision makers may not have considered how to integrate energy storage into their grid. Policy is the important set of guidelines that directs the scope and scale of storage deployment. Policymakers can begin to explore the feasibility of integrating energy storage into national markets by encouraging pilot projects and regulatory sandboxes. Once pilot projects have demonstrated potential and technical feasibility to utilities and system operators, policymakers can consider setting deployment mandates or incentive programs to support a developing energy storage industry. Concurrently, policy needs to be aligned with regulations to plainly distinguish the expectations and capabilities that energy storage should provide to the system. In sum, policy interventions can accelerate the identification and implementation of system-appropriate energy storage solutions.

\section{Inclusion of Storage in Energy Policy and Master Plans}

An energy policy master plan is a comprehensive document designed to identify linkages and opportunities between different energy sectors across the economy. Master plan documents are often required by national or subnational legislatures to provide detailed objectives toward reaching a low-cost energy system while meeting specific criteria such as a renewable energy goal or reliability target. In some regulated markets, utilities are required to submit proposals indicating how they intend to comply with statutory policy through integrated resource planning documents. Thus, including energy storage into master plans provides a signal for utilities to spur development and directs regulatory authorities to begin implementing targeted regulations. 
Korea's multifaceted approach provides one example of a country integrating energy storage into its national master plan. Korea's plan emphasizes "win-win commercialization projects" involving public-private partnerships to demonstrate the capabilities of energy storage, including a 100-MW compressed air energy storage system and a 50-MW lithium-ion battery paired with wind power (Korea MOTIE 2014). Though this provides an example of a master plan requiring the development of specific projects to serve as a sandbox for the larger market, other master plans provide capacity targets and allow utilities discretion in deciding how to meet targets.

Some other strategies are designed to achieve specific metrics of system performance indicative of storage providing a broader role in the power system. The Massachusetts Legislature mandated in 2018 the commonwealth's Department of Energy Resources to formulate policies and regulations toward a Clean Peak Program - requiring utilities to serve load with a percentage of clean energy resources during periods of peak demand (Massachusetts Department of Energy Resources 2019). The Department of Energy Resources implemented technology-agnostic policies, including renewable energy resources, storage, and demand response. The policy provides season-specific charging windows for energy storage to avoid increasing marginal emissions.

\section{Targets for Storage Deployment}

In addition to planning for energy storage through a master plan or targeted policy documents, policymakers can catalyze project development through mandated or aspirational targets. These targets can be included within the scope of renewable portfolio standards (also known as renewable purchase obligations) or can stand alone as storage-specific goals. Targets can be set in terms of either megawatts of installed capacity or megawatt-hours (MWh) of utilization and may increase over time (e.g., storage is $1 \%$ of generating capacity by 2030 and $3 \%$ by 2035 ).

Once a goal has been established, power suppliers such as utilities are generally required to indicate how the target will be met within their reporting (e.g., integrated resource plans or other documented planning processes). Regulators are also aware of these targets and must engage in rulemaking processes to meet the targets by set dates.

Renewable portfolio standards (RPS) or renewable procurement obligations are policies that require entities such as electric utilities to procure a certain amount of their generation (on a megawatt-hour basis) from renewables. Compliance with an RPS is typically measured through renewable energy certificates that are assigned for every megawatt-hour of generation from renewables and contain the legal rights to claim the environmental and social attributes caused (or avoided) by the generation of renewable energy. Including storage within an RPS through carve-outs or multipliers are common devices used by policymakers to incentivize some level of storage adoption instead of other eligible generation technologies. A carve-out requires that a certain percentage of an entity's overall RPS obligation be met from specified technologies. No U.S. states have implemented an energy storage carve-out within their RPS, but existing carveouts for other technologies such as distributed energy resources or community solar projects can serve as an example of how this may be implemented. A "multiplier" offers additional renewable energy certificates toward RPS compliance for every megawatt-hour provided by energy storage; for example, the U.S. state of Michigan offers a credit multiplier of 0.2 for all renewable electricity generated during off-peak periods and discharged during peak (DSIRE 2018; Holt 2016). 
If energy storage is included in an RPS, there are important considerations as to which technologies are eligible (i.e., pumped hydro storage, flywheels, and batteries), which energy sources can be used for charging the storage (i.e., renewables), and how renewable energy certificates are created (i.e., if a directly coupled renewable energy project charges a battery, do they both receive a renewable energy certificate, or only one?). International consensus about these issues does not exist, but guidance from national policymakers on these issues is certainly needed to ensure storage's contributions to national energy policies is being counted in a manner consistent with the intent of the law.

Outside of RPS, policymakers can create storage mandates requiring power suppliers to adopt energy storage. For instance, the U.S. state of Oregon passed a law requiring any electric utility with 25,000 or more customers to procure either 5 MWh of energy storage by 2020 or $1 \%$ of peak load, whichever is less. Implementation of this legislation was conducted by the Oregon Public Utility Commission, which regulates utilities and was responsible for approving projects (DOE et al. 2020).

In the United States, 32 states include energy storage in their policies dictating utility planning processes (Balaraman 2020). Some of these states, such as California, require utilities to meet escalating storage targets between 2014 and 2018 using a combination of utility owned systems and aggregated customer-sited systems. In the state of New York, the governor established a nonbinding target (rather than a mandatory goal) of 1,500 MW of storage by 2025 and 3,000 MW by 2030, while Massachusetts set an aspirational target of 200 MWh by 2020 (Maloney 2018a). All of these approaches serve to increase the uptake of energy storage technologies.

\section{Energy Strategy Promotes Operational Flexibility}

Operational flexibility allows for the power system to be resilient and cost-effective while ensuring future renewable energy capacity growth can be integrated smoothly. Flexibility is becoming a cornerstone of energy policies and master plans around the world as variable renewable energy growth accelerates (Zinaman and Sadamori 2018). In countries with rising electricity demand, a flexible grid ensures changing load patterns and unpredictable customer behavior will not impact the ability to dispatch the least-cost mix generation sources to reliably meet demand.

In response to changing system needs, policymakers have begun to pursue a "flexibility first" paradigm in energy policy master plans. Doing so is a policy step aimed to encourage several changes, including technology-agnostic flexibility requirements that allow any technology to compete with other resources to provide grid services, capital improvements to existing plants to improve flexibility, technical flexibility assessments as part of regular system adequacy evaluations, and the inclusion of operational flexibility in long-term planning. The resulting flexibility requirements should represent the range of anticipated system needs on different timescales, including response times and duration. Policymakers can also promote relevant markets such as intraday or real time energy and ancillary services markets to incentivize investments in and promote competition among high-performing flexible resources. 


\section{Support for Organized Knowledge Sharing and Delivery for Scale Up and Replication}

Policy can facilitate an enabling ecosystem for energy storage research and deployment. For example, public support for research and development, including pilot projects and the formation of a forum of practitioners can accelerate the deployment of promising technologies and promote increased knowledge exchanges among experts. Policymakers can also lower barriers for investments through organized data collection and reporting to enable high-quality feasibility studies for potential energy storage investments. And the creation of a designated entity responsible for implementing energy storage programs and activities can promote greater coordination among various policies.

For instance, the New York State Energy Research and Development Authority (NYSERDA) is a public benefit corporation that aims to provide objective information and analysis, innovative programs, and technical expertise to increase energy efficiency and renewable energy in the state of New York (NYSERDA 2020). As the state agency tasked with promoting the energy storage market, NYSERDA is responsible for allocating state funds to implement storage incentive programs. The agency serves as the clearinghouse for information on incentives and technical resources for installing and operating energy storage facilities, opportunities for researchers and manufacturers to develop new energy storage technologies, and the state's progress toward its clean energy goals. NYSERDA also connects technical experts through one-on-one consultations for developers and contractors to help with project siting, sizing, and economics.

\section{Domestic Industrial Policy Supports Storage Manufacturing}

Another step in promoting an enabling ecosystem for energy storage is developing the entire supply chain, including local manufacturing and assembly for storage components and trained technicians for after-sales service. Countries with existing car manufacturing and electronic supply chains are exploring mechanisms to expand this expertise to battery manufacturing. Strategies being adopted in Europe include incentivizing domestic collaboration on research and development between automobile manufacturers and companies that could adapt to produce batteries and developing strategic electric vehicle programs that leverage demand for electric vehicle battery components to accelerate domestic stationary utility-scale battery manufacturing (Beuse, Schmidt, and Wood 2018). Additional synergies can be identified with other domestic electronic manufacturing such as manufacturing of cellphones or laptops.

Domestic industrial policy can also be incorporated into RPS policies. The U.S. states of Arizona, Delaware, and Michigan offer an RPS credit-multiplier for any system manufactured or installed by an in-state workforce. Policies such as this can offer a nonmonetary subsidy for utilities to install renewable energy or energy storage devices that support the domestic industrial and construction workforce (Holt 2016).

\section{Targeted Support to Early Adopters}

Financial support offers a direct and effective way for policymakers to improve project economics or increase access to project financing for developers. Targeted financial support programs that have demonstrated successes around the world include loan guarantees, grants, tax credits, and exemptions on connection fees and funds. 
Loan guarantees involve a government entity fulfilling a guarantor role backing up a developer's financing request. If banks are unfamiliar with new storage or renewable energy technologies, they may be hesitant to provide a large amount of funding upfront without fully understanding the economic potential of the project. Typically, a loan guarantee will require a high level of project planning and technical modelling to understand the estimated revenue and risk of a given project. If projected revenue (or payback period) is adequate, the availability of government loan guarantees can provide banks with confidence in a project to provide access to financing. In 2018, the U.S. Department of Energy announced \$2 billion in loan guarantees for energy projects on Native American tribal lands (DOE 2019).

Direct financial incentives can take the form of grants paid upfront, investment-based tax credits applied against project tax liabilities, and production-based incentives provided on a permegawatt-hour basis. Criteria for the credit should be targeted to direct the types of outcomes in which policymakers are interested. For example, in the U.S., renewable energy projects paired with storage need to ensure at least $75 \%$ of charging comes from the onsite renewables in order to receive the federal investment tax credit for the battery (Elgqvist, Anderson, and Settle 2018). Such support measures have been especially productive at fostering the development of new technologies where domestic installers and developers may not have experience. Productionbased incentives, either tax credits or feed-in-tariffs, offer an alternative method of improving project economics with a focus on developing areas with high resource potential.

An alternative method of targeted support for highly impactful projects is a revolving loan fund. With this method, funds are typically used to finance energy efficiency projects that provide lower payback periods ( $\sim 10$ years or less) and offer significant value in terms of energy savings or emission reductions. The fund offers very low interest loans to these projects, whose payments are recycled to offer additional loans to other entities. Revolving loan funds have also been used for renewable energy projects, such as in Thailand, where a \$235 million dollar revolving loan fund has financed several industrial renewable energy projects while building capacity among domestic financing institutions to support increased access to private financing (CCAP 2012). The revolving loan fund model could be extended to energy storage to increase access to financing for targeted projects offering a high value to the grid.

Policymakers can also provide indirect support through, for example, financing for project planning and technical analysis or exemptions on connection fees. For any support mechanism, a technology-agnostic approach can promote innovation among competing technical solutions.

\subsection{Regulation}

As policy and technological innovations drive increased investments in energy storage, questions emerge as to how this new type of grid asset should be treated. Electricity regulations are the set of rules governing electric power sales and services, including planning, siting, and tariffs for generation, transmission, and distribution functions. Regulations can enable innovation and exploration as the needs of the power system continue to evolve and as the range of potential energy storage technologies able to meet these needs grows. Regulations should seek to establish a level playing field for energy storage to provide grid services and be compensated for those services without being overly prescriptive. 


\section{Utilities and Private Developers Allowed to Make Storage Investments}

Vertical unbundling - separation of potentially competitive segments (generation and retail) from uncompetitive segments (transmission and distribution) - has been international best practice since the 1990s (Nillesen and Pollitt 2011; Al-Sunaidy and Green 2006; Bye and Hope 2005). Systems that have undergone this type of structural reform have established regulations to govern the types of investments providers from each segment are allowed to make. Energy storage, with its ability to provide services across multiple power sector functions, may require updates to existing regulations to allow sectors that benefit from energy storage to make these investments.

For example, in the U.S. state of Texas, transmission and distribution utilities were barred from legally owning energy storage facilities because they were classified as generation assets. This rule prevented these utilities from using storage facilities to defer or avoid the need for network investments (Mai 2019). In 2019, the rule was amended to allow municipal utilities and electric cooperatives to own energy storage facilities that sell energy or ancillary services without registering as a power generator.

\section{Interconnection Processes Give Energy Storage the Right to Interconnect and Obtain Transmission Service}

Rules regarding transmission connection can present another barrier for energy storage investments. Energy storage technologies should be included in interconnection rules establishing the process for obtaining transmission service. In the U.S., Federal Energy Regulatory Commission (FERC) Order 845 expanded the definition of "generation resource" to include storage in existing interconnection rules (Konidena 2019). To reduce uncertainty for project developers, the costs for interconnection, including any necessary network upgrades and transmission service charge should be established ex ante and not updated for a reasonably long time.

In some areas, the lengthy study cycles and wait times required for interconnection can be overly burdensome for energy storage investments. Establishing an interconnection queue can help inform expectations of project timelines for developers. System operators can coordinate with transmission owners to publish a "storage feasibility map" that identifies general locations on the network that are suitable for storage development. Interconnection processes can also be updated to include expedited approval if, for example, connection occurs at the point of an existing approved renewable energy project interconnection request. Under FERC Order 845 (FERC 2019), energy storage projects could access surplus interconnection capacity and avoid the normal study cycle (with minimum completion times of 18 months) for new interconnection requests (Konidena 2019).

Through the interconnection process, regulators can remove barriers for energy storage investments and minimize uncertainty for project developers.

\section{Promotion of High-Quality, Standardized Technologies Through Safety Standards for Energy Storage Technologies}

Codes, standards, and regulations (CSR) covering the safe installation and operation of storage

technologies, including all facility components, are important to facilitate timely testing, review, 
and approval when deploying energy storage facilities (Conover 2014). For new technologies or well-established technologies being deployed for new applications, CSRs can ensure the technology is safely integrated into the system and can avoid market spoilage whereby lowquality products reduce overall demand. On the other hand, overly burdensome standards can create barriers for investments if the time and cost required for compliance makes the project uneconomic.

Energy storage technologies that have been available for some time (e.g., lead acid batteries) may already be covered by existing CSR and can be readily deployed when in compliance with those CSR. Newer technologies may require revising existing standards or developing entirely new standards to guide evaluating the technology for safety. The development of new or revised standards can be facilitated through protocols, pre-standards, and benchmark standards that can serve as the short-term basis for approval and can provide a resource for future CSR development.

Standards covering the application and installation of a technology tend to lag the development of the technology (Conover 2014). As a result, existing criteria may be inappropriately applied for new storage facilities. Regulators can minimize this lag through a proactive approach to setting CSR for new technologies. An assessment of existing CSR in relation to current and anticipated needs for energy storage systems can help regulators identify potential gaps and areas for immediate action.

The range of energy storage technologies being developed in terms of their type, chemistry, size, and other factors is driving an increased need for research and development to support the development of new CSR. Increased education, training, and technical support for the development of CSR will be critical to develop necessary standards in a timely manner for energy storage technologies.

\section{Operating Requirements for Fast-Responding Assets}

All power systems require some level of flexibility to continuously meet electricity demand and maintain equipment within safe voltage and frequency ranges. However, the need for fastresponding assets has taken on increased importance as the share of variable generation resources has increased. For example, the Electric Reliability Council of Texas (ERCOT) created a new market for fast frequency response resources - provided by storage resources to respond within 1-12 seconds to deviations in system frequency outside established boundaries. Fast frequency response from storage resources can work in either direction: charging or discharging. Since being implemented, fast frequency response services have been deployed on multiple events and successfully helped arrest falters in system frequency (Matevosyan et al. 2013). Additional changes proposed under fast frequency response as of April 2016 are detailed in Figure 1. The benefits of these proposed changes include improved reliability and flexibility, reduced amounts of reserve capacity that ERCOT needs to procure. 
Current

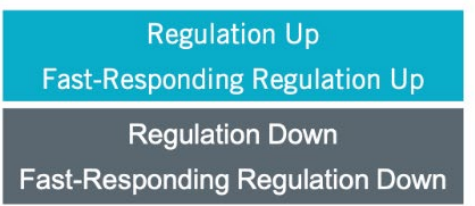

Non-Spin
Proposed

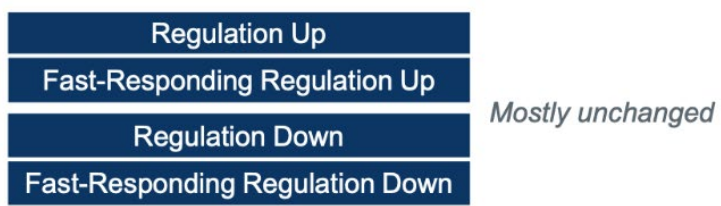

Fast Frequency Response 1

$59.8 \mathrm{~Hz}$, Limited duration

Fast Frequency Response $2 \quad 59.7$ Hz, Longer duration

Primary Frequency Response

Contingency Reserves 1

Contingency Reserves 2

SCED-dispatched

Manually dispatched

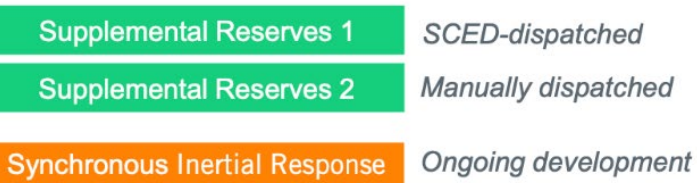

Figure 1. Fast frequency response changes to ERCOT's ancillary services ERCOT 2016

Establishing specific requirements for fast-responding assets can also increase investment opportunities for energy storage technologies, many of which are technically capable of responding to control signals faster than conventional generators. For instance, over $40 \%$ of flywheel facilities are designed for frequency regulation applications (EIA 2020; DOE et al. 2020).

\section{Electricity Services Charges Reflect the Value of and Increase Price Transparency for Energy Services}

Advanced technologies are enabling consumers and suppliers to see and respond to real-time conditions across the power grid. These advances could significantly expand the speed and accuracy of resources available to the system operator, thus leading to improved reliability and cost savings to both consumers and utilities. However, incentivizing these resources to be available and respond as needed will require price signals that capture the value of these services to the system. Though this issue is not new or specific to any single technology, energy storage technologies are increasingly cited as a resource that is not valued appropriately in calls for reforms to existing compensation mechanisms.

For instance, FERC Order 755 (FERC 2011) requires U.S. markets to adopt a two-part marketbased compensation mechanism for frequency regulation services, including a capacity payment that reflects the opportunity cost of not using the resource for another service and a market-based performance payment that rewards faster-ramping resources. In the PJM Interconnection (PJM) territory, this led to a tripling of the fast-moving resources available for frequency regulation (Tweed 2013). Because these resources can respond to signals more quickly and accurately, PJM was able to lower its regulation requirements. FERC Order 784 expands the incentives for highperformance resources by requiring public utilities to also consider speed and accuracy in assessing regulation resources (FERC 2013). 
Other approaches to improve price signals focus on capturing the value a resource provides to the system at specific times and locations. The best-known of these is wholesale market pricing that captures the value of energy supplies at different times of day. Locational marginal prices expand on this to also signal the value of supply at different locations in the network. Other products, such as firm capacity, can include seasonal or time-of-day obligations to ensure the resource is available when it is most needed.

In the past, regulators and market operators had to consider the trade-off between compensation mechanisms that were simpler to implement and those that accurately capture system value for different services. Advanced metering and control technologies are enabling more-detailed pricing mechanisms that can incentivize investments in technologies that best fit the needs of the system.

\section{Storage Able to Compete with Other Grid Assets to Provide Multiple Services}

An important step to maximize the value of energy storage to the grid is to remove regulatory barriers that prevent storage from providing grid services. This may entail amending regulations to expand the definition of generation or transmission assets or eliminating restrictions on the types of technologies eligible to provide certain services. For example, the landmark FERC Order 841 directs U.S. markets to create rules for energy storage deployments as small as $100 \mathrm{~kW}$ to participate in wholesale, capacity, and ancillary service markets on a nondiscriminatory basis alongside other assets (FERC 2018). Though FERC Order 841 seeks to remove barriers for energy storage, it gives each regional transmission organization and independent system operator discretion to design its own rules for compliance, allowing for multiple solutions. This flexibility is important while markets are still gaining experience with energy storage and many unanswered questions about how markets can best capture the value of energy storage remain. And U.S. markets are already proposing diverse approaches to comply with FERC Order 841 (John 2019; Maloney 2018b).

A central issue with is whether rules for energy storage should be based on existing technology categories or designed for a new type of market participant. For example, to participate in the capacity market, PJM proposes to apply its continuous energy requirement for pumped storage hydro to all energy storage technologies whereas the Midcontinent Independent System Operator proposes energy storage can only participate as a demand response asset. In their proposals for wholesale electricity market rules, PJM and California Independent System Operator avoid the issue of defining storage as a generation or demand resource altogether by treating charging and discharging as positive and negative bids respectively. In other jurisdictions, markets are considering new services or expanding the definition of existing services to better capture the capabilities of energy storage. EirGrid in Ireland, the European Network of Transmission System Operators for Electricity, and the Australian Energy Market Operator are all considering new services such as fast frequency response to not necessarily be "inertial" because they can be provided by energy storage resources (Akram et al. 2020).

Utilities, system operators, and markets will continue to develop new solutions to maximize the value of energy storage as they gain experience with these technologies providing new services. During this familiarization phase, regulations can remove barriers for participation while providing flexibility for experiential learning and testing new solutions as novel challenges emerge. 


\section{Storage Able to Receive Revenue for Providing Multiple Services}

Grid assets owners must be compensated for the services they provide through some combination of tariffs and/or market prices. Without a guarantee that services provided by energy storage facilities will be compensated, project developers and financial institutions may be unwilling to make the necessary investments (Bowen, Chernyakhovskiy, and Denholm 2019). Absent competitive markets, regulated utilities can recover the cost of prudent storage investments through electricity tariffs set by the regulator. In restructured markets where some form of unbundling has taken place to allow competition, the process can be more complex because energy storage can provide services that span multiple compensation sources. For instance, energy and ancillary services can be compensated through markets whereas network deferrals may be compensated as a cost of service by the utility or system operator (Sioshansi, Denholm, and Jenkin 2012). To complicate matters, some benefits of energy storage such as reduced generator cycling and ramping are often poorly priced or not priced in markets or regulated tariffs.

Despite these challenges, there is a growing agreement that enabling energy storage resources to provide multiple services, including both cost-based and market-based services maximizes the value of energy storage resources for the system and to consumers. In fact, commenters to FERC's 2017 policy statement on whether energy storage should be able to receive revenue for multiple services noted "the key question is not whether to allow multiple use applications for electric storage resources but how to allow and enable such applications" (FERC 2017). FERC noted that any approach must address the:

1. Potential for combined cost-based and market-based revenue to result in double recovery of costs

2. Potential for cost-based rates to distort competitive prices in the wholesale market

3. Level of control in the operation of a storage resource by the system operator that may jeopardize its ability to participate in competitive markets.

Power systems around the world are seeking solutions to the issues of how to value the wide range of services that energy storage can provide and compensate owners for these services. For instance, the Midcontinent Independent System Operator is developing rules for storage facilities built as transmission assets for reliability and economic purposes that are eligible for cost-based payments to also participate in the wholesale market (Konidena 2020). The New York Independent System Operator offers a salient example of creating a new category of "energy storage resources" that are able to provide multiple services; the framework it created allows energy storage resources "dual participation," wherein storage can switch between offering retail and offering wholesale market capabilities. For instance, a storage project can act as a non-wire transmission deferral project during the summer so a retail utility can ease congestion and as a wholesale market participant during other seasons (Noriega 2017). 


\section{The Energy Storage Readiness Assessment Framework}

Section 2 outlined the range of technical and nontechnical factors that can enable energy storage investments. This section combines these 20 criteria to form our energy storage readiness assessment, organized by three topics (Table 2).

Table 2. Components of the Energy Storage Readiness Assessment

\begin{tabular}{|c|c|c|}
\hline Topics & No. & Criteria \\
\hline \multirow{7}{*}{$\begin{array}{l}\text { System } \\
\text { Characteristics }\end{array}$} & 1 & Low or decreasing load factor in electricity demand \\
\hline & 2 & Inadequate or costly provision of ancillary services \\
\hline & 3 & Inadequate or costly supply options during peak demand periods \\
\hline & 4 & Increasing levels of transmission congestion \\
\hline & 5 & Proposed network upgrades with low anticipated utilization \\
\hline & 6 & Low flexibility in the generation mix \\
\hline & 7 & Increasing curtailment of variable renewable energy \\
\hline \multirow{6}{*}{ Policy } & 8 & Inclusion of storage in energy policy and master plan \\
\hline & 9 & Targets for storage deployment \\
\hline & 10 & Energy strategy promotes operational flexibility \\
\hline & 11 & $\begin{array}{l}\text { Support for organized knowledge sharing and delivery for scale up and } \\
\text { replication }\end{array}$ \\
\hline & 12 & Domestic industrial policy supports storage manufacturing \\
\hline & 13 & Targeted support to early adopters \\
\hline \multirow{7}{*}{ Regulation } & 14 & Utilities and private developers allowed to make storage investments \\
\hline & 15 & $\begin{array}{l}\text { Interconnection processes give storage the right to interconnect and } \\
\text { obtain transmission service }\end{array}$ \\
\hline & 16 & $\begin{array}{l}\text { Promotion of high-quality standardized technologies through safety } \\
\text { standards for storage technologies }\end{array}$ \\
\hline & 17 & Operating requirements for fast-responding assets \\
\hline & 18 & $\begin{array}{l}\text { Electricity service charges reflect value of and increase price } \\
\text { transparency for energy services }\end{array}$ \\
\hline & 19 & $\begin{array}{l}\text { Storage able to compete with other grid assets to provide multiple } \\
\text { services }\end{array}$ \\
\hline & 20 & Storage able to receive revenue for providing multiple services \\
\hline
\end{tabular}


To complete the readiness assessment, each criterion in Table 2 is assigned a color based on the evaluation scheme in Figure 3.

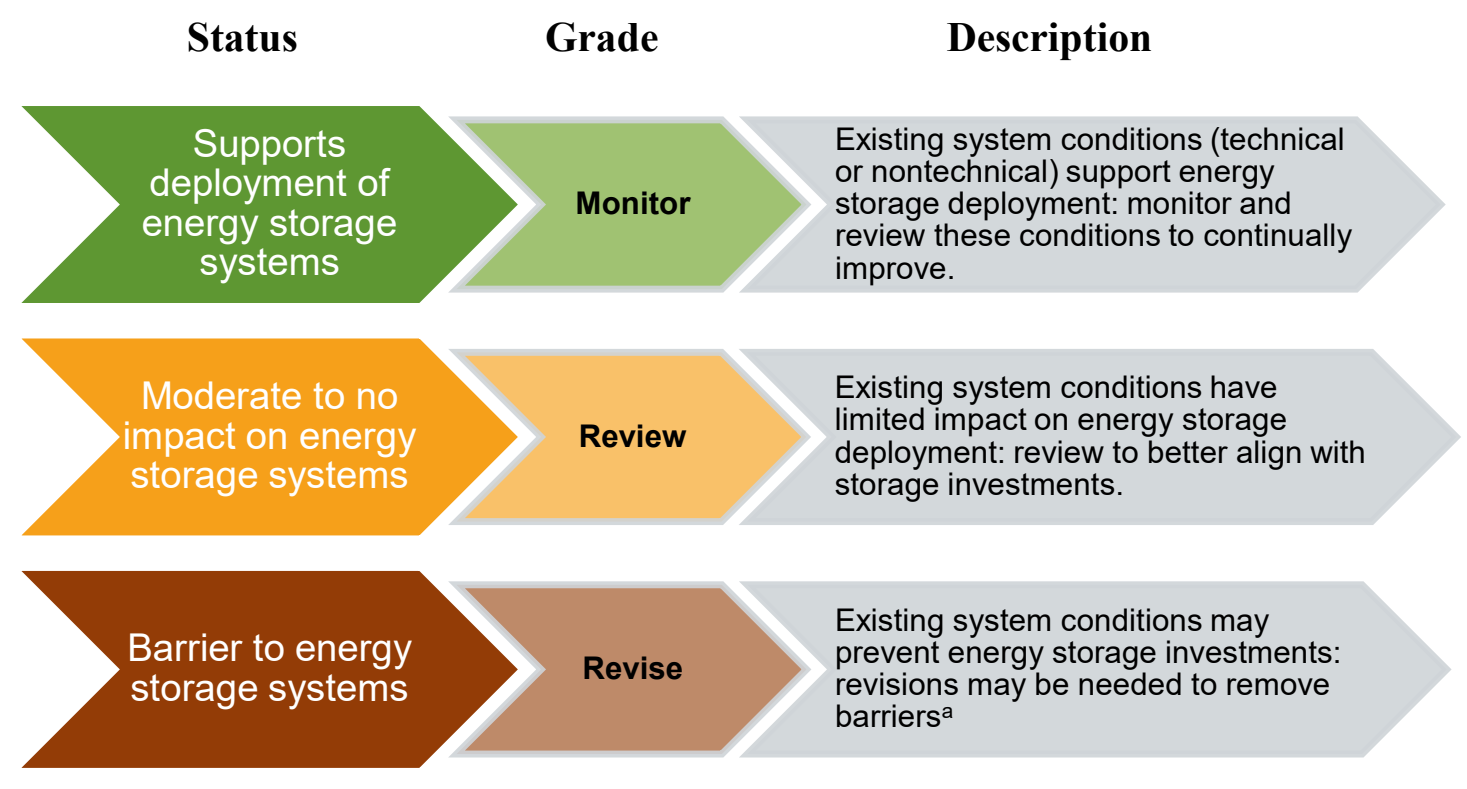

Figure 2. Evaluation scheme for energy storage readiness assessments

${ }^{a}$ Revisions may not be recommended for system characteristics where conditions that are good for the overall system (i.e., high levels of system flexibility and reliability) may not support energy storage investments.

The "Monitor" grade indicates existing system conditions (technical or nontechnical) support energy storage deployment. These conditions should be monitored as conditions change to identify areas for continued improvement. In cases where system conditions have limited impact - positive or negative - on energy storage deployment, a grade of "Review" can be given. This indicates the need to review and, if desirable, update policy or regulatory frameworks to better align with energy storage deployment. Finally, criteria that present a barrier to energy storage are given a grade of "Revise" indicating action may be required to remove existing conditions that may be preventing investments in energy storage.

\section{Conclusions}

The energy storage readiness assessment, which consists of 20 technical, policy, and regulatory criteria that enable energy storage investments, is intended to identify the barriers and opportunities for utility-scale energy storage within a given power system, policy, and regulatory environment.

The energy storage readiness assessment is designed to allow policymakers and regulators to quickly gauge how well existing policy and regulatory frameworks support investments in energy storage. Though this report draws from relevant examples from the U.S. and abroad to illustrate how energy storage challenges are being addressed in practice, the readiness assessment framework is not intended to recommend specific policy or regulatory solutions. Rather it can be used to illustrate how compatible a given system is for energy storage investments and to identify priority areas for attention. In fact, it is designed to be applied to any 
jurisdiction regardless of its governance, regulatory, or market structure. However, a given system may need to be reassessed periodically or as system conditions change.

As a next step, we will apply the energy storage readiness assessment developed in this report to individual countries in South Asia. The resulting country-specific evaluations of policy and regulatory environments for energy storage will be presented in subsequent reports. 


\section{References}

Abraham, Allen Tom. 2019. "Battery Storage in India: Energy the Decade of Growth." Bloomberg New Energy Finance.

Akhil, Abbas, Georgianne Huff, Aileen Currier, Benjamin Kaun, Dan Rastler, Stella Bingqing Chen, Andrew Cotter, Dale Bradshaw, and William Gauntlett. 2015. "DOE/EPRI Electricity Storage Handbook in Collaboration with NRECA." doi:10.2172/1431469. https://www.sandia.gov/ess-ssl/publications/SAND2015-1002.pdf

Akram, Umer, Mithulananthan Nadarajah, Rakibuzzaman Shah, and Federico Milano. 2020. "A Review on Rapid Responsive Energy Storage Technologies for Frequency Regulation in Modern Power Systems." Renewable and Sustainable Energy Reviews 120 (March): 109626. https://doi.org/10.1016/j.rser.2019.109626.

Al-Sunaidy, A., and R. Green. 2006. "Electricity Deregulation in OECD (Organization for Economic Cooperation and Development) Countries." Energy, Electricity Market Reform and Deregulation, 31 (6): 769-87. https://doi.org/10.1016/j.energy.2005.02.017.

Aznar, Alexandra, Thomas Bowen, and Owen Zinaman. 2020. "An Overview of Behind-theMeter Solar-Plus-Storage Program Design: With Considerations for India." NREL/TP-7A4074131, 1665766, MainId:6343. https://doi.org/10.2172/1665766.

Balaraman, Kavya. 2020 " 2020 Outlook: Renewables, Resilience and Reliability Needs Will Drive Storage.” Utility Dive. 2020. https://www.utilitydive.com/news/2020-outlook-renewablesresilience-and-reliability-needs-will-drive-stora/569612/

Beuse, Martin, Tobias S. Schmidt, and Vanessa Wood. 2018. “A 'Technology-Smart' Battery Policy Strategy for Europe.” Science 361 (6407): 1075-77. https://doi.org/10.1126/science.aau2516.

Bowen, Thomas, Ilya Chernyakhovskiy, and Paul Denholm. 2019. "Grid-Scale Battery Storage: Frequently Asked Questions". Golden, CO: National Renewable Energy Laboratory. NREL/TP6A20-74426. https://www.nrel.gov/docs/fy19osti/74426.pdf.

Bye, Torstein, and Einar Hope. 2005. "Deregulation of Electricity Markets: The Norwegian Experience." Economic and Political Weekly 40 (50): 5269-78.

CCAP. 2012. "Revolving and ESCO Funds for Renewable Energy and Energy Efficiency Finance." Washington, DC: Center for Clean Air Policy. http://ccap.org/assets/CCAPBooklet_Thailand.pdf.

CEA. 2019. "Measures to Promote Hydro Power Sector." Delhi: Central Electricity Authority. http://cea.nic.in/reports/others/hydro/hpi/hydro measures.pdf.

_ 2020. "All India Installed Capacity (in MW) of Power Stations." Delhi: Central Electricity Authority. http://cea.nic.in/reports/monthly/installedcapacity/2020/installed_capacity04.pdf. 
Chernyakhovskiy, Ilya, Sam Koebrich, Vahan Gevorgian, and Jaquelin Cochran. 2019. "GridFriendly Renewable Energy: Solar and Wind Participation in Automatic Generation Control Systems.” NREL/TP-6A20-73866. Golden, CO: National Renewable Energy Laboratory. https://www.nrel.gov/docs/fy19osti/73866.pdf

Cochran, J., M. Miller, O. Zinaman, M. Milligan, D. Arent, B. Palmintier, M. O'Malley, et al. 2014. "Flexibility in 21 st Century Power Systems." NREL/TP-6A20-61721, 1130630. https://doi.org/10.2172/1130630.

Conovor, DR. 2014. Inventory of Safety-related Codes and Standards for Energy Storage Systems with some Experiences related to Approval and Acceptance. Richland, WA: Pacific Northwest National Laboratory. PNNL-23618. https://www.sandia.gov/essssl/docs/safety/ESS_Inventory_9-15-14_PNNL_23618.pdf

Denholm, Paul, Jennie Jorgenson, Marissa Hummon, Thomas Jenkin, David Palchak, Brendan Kirby, Ookie Ma, and Mark O'Malley. 2013. "The Value of Energy Storage for Grid Applications." NREL/TP-6A20-58465. Golden, CO: National Renewable Energy Laboratory. https://www.nrel.gov/docs/fy13osti/58465.pdf.

Denholm, Paul, and Robert Margolis. 2018. "The Potential for Energy Storage to Provide Peaking Capacity in California under Increased Penetration of Solar Photovoltaics." NREL/TP6A20-70905. Golden, CO: National Renewable Energy Laboratory. https://www.nrel.gov/docs/fy18osti/70905.pdf

Denholm, Paul, Yinong Sun, and Trieu Mai. 2019. "An Introduction to Grid Services: Concepts, Technical Requirements, and Provision from Wind." Renewable Energy, 52.

DOE. 2019. "Tribal Energy Loan Guarantee Program." Washington, DC: U.S. Department of Energy. https://www.energy.gov/lpo/tribal-energy-loan-guarantee-program.

DOE, Sandia National Laboratories, Pacific Northwest National Laboratory, and Oak Ridge National Laboratory. 2020. "Global Energy Storage Database.” 2020. https://www.sandia.gov/ess-ssl/global-energy-storage-database-home/.

Donohoo-Vallett, Pearl, Michael Milligan, and Bethany Frew. 2015. "Capricious Cables: Understanding the Limitations and Context of Transmission Expansion Planning Models." The Electricity Journal 28 (9): 85-99. https://doi.org/10.1016/j.tej.2015.10.003.

DSIRE. 2018. "Michigan Renewable Energy Standard.” July 2018. https://programs.dsireusa.org/system/program/detail/3094.

EIA. 2020. "Form EIA-860 Detailed Data with Previous Form Data (EIA-860A/860B)." Washington, DC: Energy Information Administration. https://www.eia.gov/electricity/data/eia860/. 
Ela, E., and R.B. Hytowitz. 2019. "Ancillary Services in the United States: Technical Requirements, Market Designs and Price Trends." 3002015670. Palo Alto, CA: Electric Power Research Institute. https://www.offshorewindadvisory.com/wp-content/uploads/2019/07/EPRIAncillary-Services.pdf

Elgqvist, Emma, Kate Anderson, and Edward Settle. 2018. "Federal Tax Incentives for Energy Storage Systems.” NREL/FS-7A40-70384. Golden, CO: National Renewable Energy Laboratory. https://www.nrel.gov/docs/fy18osti/70384.pdf

ERCOT. 2016. "Future Ancillary Services: Preparing to Maintain Reliability on a Changing Grid." April 2016.

http://www.ercot.com/content/wcm/lists/89476/FAS TwoPager_April2016 FINAL.pdf.

Eyer, Jim. 2009. "Electric Utility Transmission and Distribution Upgrade Deferral Benefits from Modular Electricity Storage." SAND2009-4070. Albuquerque, NM: Sandia National Laboratories. https://prod-ng.sandia.gov/techlib-noauth/access-control.cgi/2009/094070.pdf

FERC. 2011. "Frequency Regulation Compensation in the Organized Wholesale Power Markets, Order 755". Washington, DC: Federal Energy Regulatory

Commission. https://ferc.gov/sites/default/files/2020-06/OrderNo.755-A.pdf

- 2013. "Third-Party Provision of Ancillary Services; Accounting and Financial Reporting for New Electric Storage Technologies, Order 784." Washington, DC: Federal Energy Regulatory Commission. https:/www.ferc.gov/sites/default/files/2020-06/OrderNo.784.pdf

2017. "Utilization of Electric Storage Resources for Multiple Services When Receiving Cost-Base Rate Recovery.” Docket No. PL17-2000. Washington, DC: Federal Energy Regulatory Commission. https://www.ferc.gov/sites/default/files/2020-04/E-2 34.pdf

2018. "Electric Storage Participation in Markets Operated by Regional Transmission Organizations and Independent System Operators, Order No. 841." Washington, DC: Federal Energy Regulatory Commission. https://ferc.gov/sites/default/files/2020-06/Order-841.pdf

- 2019. "Reform of Generator Interconnection Procedures and Agreements, Order No. 845-A.” Washington, DC: Federal Energy Regulatory Commission. https://www.ferc.gov/sites/default/files/2020-06/Order-845-A.pdf

Frew, Bethany, Wesley Cole, Nina Vincent, Andrew Reimers, and Robert Margolis. 2018. "Impact of Dynamic Storage Capacity Valuation in Capacity Expansion Models." NREL/CP6A20-71462. Golden, CO: National Renewable Energy Laboratory. https://www.nrel.gov/docs/fy18osti/71858.pdf

Gimon, E., Orvis, R., and Aggarwal, S. 2015. "Renewables Curtailment: What We Can Learn From Grid Operations in California and the Midwest." Greentech Media. March 23, 2015. https://www.greentechmedia.com/articles/read/renewables-curtailment-in-california-and-themidwest-what-can-we-learn-from. 
Gumilar, Langlang, Arif Nur Afandi, Wahyu Sapto Nugroho, and Mokhammad Sholeh. 2020. "Load Factor Improvement on Daily Load Curve Using Pump Storage to SavingProduction Cost." In 2020 International Conference on Smart Technology and Applications (ICoSTA), 1-6. https://doi.org/10.1109/ICoSTA48221.2020.1570607250.

Holt, Edward. 2016. "Does Energy Storage Fit in an RPS?" Clean Energy States Alliance. https://www.cesa.org/resource-library/resource/does-energy-storage-fit-in-an-rps/.

Jain, Himanshu, Gab-Su Seo, Eric Lockhart, Vahan Gevorgian, and Benjamin Kroposki. 2020. "Blackstart of Power Grids with Inverter-Based Resources: Preprint." NREL/CP-5D00-75327. Golden, CO: National Renewable Energy Laboratory. https://www.nrel.gov/docs/fy20osti/75327.pdf

John, J. 2019. “New York’s Grid Operator Grapples With the Energy Transition.” May 2019. https://www.greentechmedia.com/articles/read/new-york-states-grid-operator-faces-big-changesdriven-by-renewables-carbon.

Konidena, Rao. 2019. "FERC Order 841 levels the playing field for energy storage." MRS Energy \& Sustainability, 6, E5. doi:10.1557/mre.2019.5

— 2020. "It Is Time to Allow Third-Party Aggregators in the MISO States." Renewable Energy World. July 10, 2020. https://www.renewableenergyworld.com/2020/07/10/it-is-time-toallow-third-party-aggregators-in-the-miso-states/.

Korea MOTIE. 2014. "Korea Energy Master Plan Outlook \& Policies to 2035.” Korea Ministry of Trade, Industry \& Energy. https://policy.asiapacificenergy.org/sites/default/files/2nd\%20Energy\%20Master\%20Plan.pdf

Mai, HJ. 2019. "Texas Utilities Poised to Get Ability to Own Energy Storage Assets." Utility Dive. August 13, 2019. https://www.utilitydive.com/news/texas-utilities-poised-to-get-newability-to-own-energy-storage-assets/560797/

Maloney, Peter. 2017. "Storage for T\&D Deferral Works, Arizona Public Service Finds in Tonto National Forest." Utility Dive, November 2017. https://www.utilitydive.com/news/storage-fortd-deferral-works-arizona-public-service-finds-in-tonto-natio/511485/.

Maloney, Peter. 2018a. "New York Sets 3 GW Storage Target, Doubles Efficiency Goals for Utilities." Utility Dive. December 2018. https://www.utilitydive.com/news/new-york-psc-setsstates-energy-storage-target-at-3-gw-by-2030/544371/.

- 2018b. "As Grid Operators File FERC Order 841 Plans, Storage Floodgates Open Slowly." Utility Dive. December 11, 2018. https://www.utilitydive.com/news/as-grid-operatorsfile-ferc-order-841-plans-storage-floodgates-open-slowly/543977/.

Massachusetts Department of Energy Resources. 2019. "The Clean Peak Energy Standard." Massachusetts Department of Energy Resources. https://www.mass.gov/doc/drafts-cps-regsummary-presentation/download. 
Matevosyan, Julia, Greg Thurnher, Warren Katzenstein, and Andrew Stryker. 2013. "ERCOT Reserve Adequacy Study for the Future System Development Scenarios with Large Share of Renewable Energy Resources." In 2013 IEEE Grenoble Conference, 1-6. Grenoble, France: IEEE. https://doi.org/10.1109/PTC.2013.6652446.

McCarthy, Rory, and Dan Eager. 2020. "Europe Power System Flexibility: The Essential Ingredient for Decarbonization," Wood Mackenzie.

Nillesen, Paul H. L., and Michael G. Pollitt. 2011. "Ownership Unbundling in Electricity Distribution: Empirical Evidence from New Zealand." Review of Industrial Organization 38 (1): 61-93. https://doi.org/10.1007/s11151-010-9273-5.

Noriega, Daniel F. 2017. "Energy Storage Integration: Aggregations," PowerPoint for Market Issues Working Group, Rensselaer, New York, November 2, 2017. http://www.nyiso.com/public/webdocs/markets_operations/committees/bic_miwg/meeting_mate rials/2017-11-02/Energy\%20Storage\%20I\%20O\%20MIWG\%2017\%2011\%2002.pdf

NYSERDA. 2020. "NYSERDA - New York State Energy Research \& Development Authority NYSERDA.” Albany, NY: New York State Energy Research and Development Authority. https://www.nyserda.ny.gov/.

O’Neill, Barbara, James Elsworth, Todd Levin, Travis Douville, and Juliet Homer. 2019. "Load Factor and Unserved Energy Webinar," NREL/PR-7A40-75311. Golden, CO: National Renewable Energy Laboratory.

Penn State. 2019. "The Curious Case of the Negative Price." EBF 483: Introduction to Electricity Markets. 2019. https://www.e-education.psu.edu/ebf483/node/717.

Shenot, John, Jim Lazar, and Jessica Shipley. 2018. "Rate Design in the Future." Regulatory Assistance Project. https://www.raponline.org/knowledge-center/rate-design-future/

Sioshansi, Ramteen, Paul Denholm, and Thomas Jenkin. 2012. "Market and Policy Barriers to Deployment of Energy Storage." Economics of Energy and Environmental Policy, January. https://pdfs.semanticscholar.org/a188/e9578e0d2319257cae3db2f1e0c88475348a.pdf.

Tweed, Kathrine. 2013. "Faster Frequency Regulation Triples in PJM." Greentech Media. November 8, 2013. https://www.greentechmedia.com/articles/read/faster-frequency-regulationtriples-in-pjm.

Zinaman, Owen, and Keisuke Sadamori. 2018. "Status of Power System Transformation 2018: Advanced Power Plant Flexibility." Paris: International Energy Agency and $21^{\text {st }}$ Century Power Partnerhsip. https://webstore.iea.org/status-of-power-system-transformation-2018 